\title{
As possibilidades e desafios do relato biográfico: biografia \& história: hagiografia, trajetórias e prosopografia
}

\author{
The possibilities and challenges of a biographical account: \\ Biography \& History: hagiography, trajectories and prosopography
}

Vagno Batista Ribeiro*

\begin{abstract}
Resumo
Nas últimas décadas, o estudo biográfico voltou a ter destaque a partir daquilo que François Dosse chamou de Idade Hermenêutica, a saber, a possibilidade do estudo biográfico por meio da dinâmica compreensiva e teórica de novos postulados epistemológicos que dão aos indivíduos lugar privilegiado na composição narrativa. Neste sentido, o presente artigo busca analisar alguns elementos acerca do estudo biográfico no sentido de elencar possibilidades e desafios que se postam à frente do historiador. O texto a seguir está organizado da seguinte maneira: uma breve reflexão acerca da Escrita Biográfica, seguida de um apanhado a respeito da vinculação entre real e ficcional na narrativa de vidas, concluindo por uma análise das formas reelaboradas ao longo da história das biografias, quais sejam, a hagiografia, os relatos de vidas e a prosopografia como elementos importantes na elaboração de um estudo biográfico.
\end{abstract}

\section{Palavras-chave}

Estudo Biográfico. Hagiografia. Trajetória de Vida. Prosopografia.

\begin{abstract}
In these last decades the biographical study has gained importance again based on what François Dosse called, the Hermeneutic Age, that is, the possibility of doing biographical studies through the comprehensive and theoretical dynamics of new epistemological postulates which give individuals a privileged place in the narrative composition. In this sense, this article seeks to analyze some elements about the biographical study in the sense of listing possibilities and challenges which are placed before the historiographer. The following text is organized in the following way: a brief reflection about the Biographical Writing, followed by a summary regarding the connection between real and fictional in life narratives, concluding with an analysis of the ways biographies have been reelaborated throughout history, that is to say, hagiography, life stories and
\end{abstract}

[Texto recebido em maio de 2018 e aceito em maio de 2018, com base na avaliação cega por pares realizada por pareceristas ad hoc]

* Doutorando em História (Universidade do Vale do Sinos). E-mail: profwagner2006@gmail.com 
prosopography as important elements in the elaboration a biographical
study.

Keywords

Biographical Study. Hagiography. Life Trajectory. Prosopography.

\section{Introdução}

A partir da década de 1980, houve uma renovada produção científica a respeito das possibilidades do estudo biográfico. A década de 1960 já havia dado relevantes impulsos às novas epistemologias que surgiam no embate com as grandes narrativas que tinham dominado grande parte do século XX. O marxismo, positivismo, funcionalismo, a psicanálise e o estruturalismo, entre outras grandes narrativas, foram questionadas quanto ao seu caráter prometeico de conceder aos indivíduos aquelas grandes realizações de felicidade.

A pesquisa biográfica elaborada ao longo dos séculos flertou com as várias formas de narrativa acerca da verdade. Desde a antiguidade, a biografia serve para dar espaço aos grandes nomes da história. Na modernidade, as novas descobertas científicas passaram a colocar outros desafios ao estudo biográfico. A exigência documental, a necessidade empírica dos fatos, as formas elaboradas de organização estrutural das vidas individuais como reflexos dos grandes acontecimentos, entre outros, passou por reelaborações que vincularam as técnicas de pesquisa aos âmbitos antes não investigados do cotidiano e das mentalidades. Ficando o estudo biográfico quase sempre atrelado à denotação de um período histórico por meio da vida individual como exemplar de uma época, que possuía em si as manifestações da cultura e da sociedade como a calcificação do tempo em indivíduos exemplares.

O presente artigo busca refletir acerca da relevância do estudo biográfico. Para tanto, serão abordadas algumas problemáticas levantadas pelo historiador francês François Dosse em sua obra fundamental, O Desafio Biográfico: escrever uma vida, e que estão relacionadas aos problemas que uma pesquisa relativa a uma vida levanta, a saber, quais os parâmetros que permitem abordar uma biografia que seja tomada como problema, e não apenas como epifenômeno de uma época ou de uma coletividade. ${ }^{1}$

\section{O que é escrita biográfica?}

Para se compreender a escrita biográfica, é necessário realizar aqui um breve resgate histórico da percepção acerca dos traços que compõem a organização de sentidos que giram em torno da relação entre a vida de uma determinada pessoa, e suas várias formas de memorar o transcorrido no processo da temporalidade, e seus efeitos sobre as pessoas que a tomam como significativa. Há, de acordo com vários pesquisadores, certa

1 DOSSE, François. O Desafio Biográfico: escrever uma vida. São Paulo: EDUSP, 2009. 
oscilação no que diz respeito à valorização dos escritos acerca das vidas dos indivíduos tanto conhecidos, figuras de renome histórico como Napoleão Bonaparte, quanto desconhecidos, figuras desconhecidas como os trabalhadores de uma fábrica ou um cidadão de rua. ${ }^{2} \mathrm{O}$ historiador francês François Dosse ressalta que dentre os modelos de relatos biográficos, que se alternaram ao longo da história, encontram-se aqueles que, respectivamente, valorizam as ações de heróis e heroínas, aqueles que valorizam a coletividade e aqueles, mais recentes, que valorizam as perspectivas interacionais e interpretativas entre narrador e narrado, um viés hermenêutico emolduraria esse tipo de narrativa. $\mathrm{O}$ autor francês fala em idades heroica, coletiva e hermenêutica. A idade heroica, dentre os quais estariam os romanos Plutarco (Vidas Paralelas) e Suetônio (A vida dos Doze Césares), os hagiógrafos da Europa Medieval, também os modernos Maquiavel (A vida de Castruccio Castracani), Thomas Carlyle (História de Frederico II da Prússia), dentre outros, estaria ocupada em entrelaçar um misto de realidade e ficção, vincularia sua narrativa na linearidade temporal, considerando os fatos ordenados cronologicamente a partir da infância seguindo à maturidade no intuito de conformar a escrita na qual a vida do indivíduo estaria orientada essencialmente pelo seu destino, ou seja, desde o início, a trajetória do herói estava marcada pelas suas grandes ações. Segundo as considerações de François Dosse, o herói de Plutarco é:

Definido como um ser não sujeito a regras, marcado pela desmedida (hýbris), esse herói está, por definição, sujeito às tentações do descomedimento. Deve, pois, redobrar a vigilância a fim de não soçobrar nos piores escolhos. Trata-se de uma lição moral que se pretende sugestiva para não importa qual leitor, e Plutarco se dirige primeiro a seus contemporâneos e sucessores. Para além da singularidade dos percursos relatados, o que ele almeja é a encarnação dos valores abstratos [...] Plutarco utiliza a metáfora, repisada até hoje no gênero biográfico, que consiste em aproximar sua obra do retrato feito pelo pintor, com a dupla ideia de fidelidade imprescindível ao modelo e criatividade não menos imperiosa do autor $[\ldots] \cdot{ }^{3}$

Para o autor, Plutarco se permitia fugir ao estrito esquema da história - cujo objetivo seria alcançar a verdade - para elaborar uma narrativa mais próxima ao cotidiano psicológico de seus leitores, uma biografia como magistra vitae. Esse modelo de construção de figuras heroicas foi reproduzido na Idade Media nas assim chamadas hagiografias, isto é, na vida de santos e santas, narrada com cores distantes do ser humano comum, ou seja, do camponês. Neste tema, Dosse elabora uma discussão sobre o conflito existente entre a

2 BORGES, Raquel Czarneski. A Escrita Biográfica: reflexões acerca das possibilidades narrativas. XII ENCONTRO ESTADUAL DE HISTÓRIA ANPUH/RS, de 11 a 14/08/2014, Universidade do Vale do Rio dos Sinos - UNISINOS - São Leopoldo, RS - Brasil. Disponível em: <http://www.eeh2014.anpuhrs.org.br/resources/anais/30/1405476586_ARQUIVO_aescritabiograficatexto.pdf>. Acesso em: 08 mar. 2018.

3 DOSSE, 2009, p. 129. 
areté - a virtude - e a práxis - a maneira pela qual os aspectos da humanidade conflitam diante da ação colocada à prova. A vida real é encarada por meio da coragem, a santidade é resultado da beatitude (virtude) de indivíduos "nobres". Já a idade modal, a "biografia modal", se caracterizaria pela narrativa na qual o herói individual cederia espaço para a narrativa sobre a nação, sobre a coletividade, sobre os grandes eventos estruturais, ela passaria a se orientar para os grandes processos históricos, dentre estas narrativas estariam Jules Michelet (A História da França) que encarnaria esse momento de passagem, uma vez que em seu itinerário intelectual não seria a respeito de indivíduos, mas da própria França como ser vivo, isto é, o herói individual cede espaço para a narrativa sobre a nação. O sujeito da história, neste modelo de narrativa, encontra seu valor apenas quando é capaz de realizar a transmissão dos modos, costumes e comportamentos dos indivíduos associados a uma estrutura social abrangente. Segundo Dilthey, a biografia seria o meio privilegiado de acesso ao universal captado culturalmente em indivíduos singulares. ${ }^{4} \mathrm{O}$ século XIX se caracteriza pela estatística e pelas estruturas omniabrangentes nas quais os indivíduos ocupariam lugares pré-determinados nas estruturas tanto sociais quanto biológicas, ou nacionais, ou mesmo de classe. Por sua vez, a idade hermenêutica se caracterizaria pela: "[...] variação do enfoque analítico, pela mudança constante da escala, que permitem chegar a significados diferentes com respeito às figuras biografadas". ${ }^{5}$ Há um nível mais complexo entre os pressupostos dos biógrafos e dos modos de apreensão dos biografados que estabelecem formas de compreensão que melhor concatenam aspectos da sociologia e da psicologia aos tópicos políticos que englobam os indivíduos.

Hoje já se compreende bem que a História é um fazer levado a cabo pelo próprio historiador e, portanto, até certo ponto depende da ficção. Diga-se o mesmo do biógrafo, o qual ficcionaliza seu objeto e torna-o, por isso mesmo, inalcançável, apesar do efeito do vivido que com isto obtém. [...] Em todos os domínios que dependem da transversalidade, a escrita biográfica dá um passo à frente, pois se estriba num entreleçamento de disciplinas que abre caminho para hipóteses não reducionistas. ${ }^{6}$

O aparecimento da palavra biografia nos dicionários modernos data do século XVII, e indica uma qualidade de "gênero híbrido". Trata-se de mesclar verdades e ficções num processo de constante revisão da história como campo de disputa interpretativa. Muito embora a riqueza de um estudo biográfico esteja justamente no alargamento daquilo que Dosse estabelece para o "ato de escrever uma vida", isto é, o que é múltiplo, trans-histórico, perpassado por variadas visões e valorações, a construção de um perfil vincula-se aos pressupostos sociais e culturais do biógrafo seja a construção de uma trajetória, de um relato de vida, de um estudo autobiográfico ou de uma biografia

\footnotetext{
DILTHEY, Wilhelm. A construção do mundo histórico nas ciências humanas. São Paulo: EDUNESP, 2010. DOSSE, 2009, p. 359.

DOSSE, 2009, p. 71; 122.
} 
psicológica, de biografemas ou ainda de hagiografias, bem como a construção de uma biografia jornalística ou mesmo como um ensaio biográfico.

\section{Biografia e História: entrelaçamentos entre o real e o ficcional}

Os séculos XIX e XX fundaram a ciência histórica moderna. Os grandes eventos e narrativas estavam no centro dos debates. Grandes correntes de pensamento cultivavam o gosto pelos grandes acontecimentos como o marxismo, o positivismo, o estruturalismo, a psicanálise, o funcionalismo, etc, galvanizavam as narrativas acerca dos eventos. "Nesta perspectiva, o domínio econômico-social era o eixo de observação predileto dos historiadores, preocupados em desvendar o mundo histórico em sua processualidade". ${ }^{7}$ A partir dos anos de 1960, as grandes narrativas passam a ser criticadas de forma inovadora. $\mathrm{O}$ estudo biográfico suscitou novas preocupações com trabalhos de pesquisa mais rigorosos que demonstravam as tensões existentes entre a ação humana e as estruturas sociais, dando aos personagens singulares e aos seus meio ambientes aspectos dialéticos que permitiam perspectivas micro e macrossociais diferenciadas, assegurando à História um caráter processual eivado de sujeitos concretos, “[...] a biografia histórica nova, sem reduzir as grandes personagens a uma explicação sociológica, esclarece-as pelas estruturas e estuda-as através de suas funções e papéis". ${ }^{8}$ A própria vida e sua vitalidade ensejam vieses que perpassam os modos psicológicos, as formas estruturantes de enquadrar a realidade, pois "[...] o indivíduo como força motriz do mundo encarna em si o sentido do todo, da comunidade, em relação ao qual ele igualmente age, constituindo sua própria subjetividade" ${ }^{9}$

Especificamente a partir dos anos de 1980, houve uma busca de novos vieses que rompessem com o estruturalismo e com as generalizações demasiadas na interpretação da história, o que Dosse caracteriza como idade hermenêutica. Várias formas de fazer história a partir da biografia surgem. Exemplo clássico são as obras de caráter existencialista de Jean Paul Sartre como O Idiota da Família: Gustave Flaubert de 1821 à 1857. Dosse fala que:

[...] Sartre, por seu namoro com o marxismo, reavaliará mais tarde o peso das condições objetivas e históricas que afetam o destino das pessoas, bem como o significado das situações concretas capazes de, frequentemente, impor limites estreitos à liberdade individual. Ele não renunciará à sua postura existencialista, mas atentará mais para a eficácia das mediações

7 AVELAR, Alexandre de Sá. Escrita da História, Escrita Biográfica: limites, tensões e possibilidades. ANAIS DO XX ENCONTRO REGIONAL DE HISTÓRIA: História e Liberdade. ANPUH/SP - UNESP 06 a 10 de setembro de 2010, Franca. CD-ROM.

8 LE GOFF, Jacques. A história nova. São Paulo: Martins Fontes, 1990. p. 7-8.

9 AVELAR, Alexandre de Sá. Escrita biográfica e escrita da história no pensamento de Wilhelm Dilthey. Dimensões, v. 38, p. 120-142, jan./jun. 2017. Disponível em: <www.periodicos.ufes.br/dimensoes/article/viewFile/16809/11599>. Acesso em: 05 abr. 2018. 
entre os indivíduos, tomados em sua concretude, e a porção de liberdade que permanece irredutível e que podemos recuperar pela práxis. ${ }^{10}$

O autor francês diz que há uma valorização do uso da história oral, do indivíduo e da narrativa, da micro-história de Carlo Guinzburg (1987) com O Queijo e os Vermes, 11 da história cotidiana de Jacques Le Goff (2002) com o São Luís,12 e da bio-história de Michel Foucault (1977) com o Eu, Pierre Riviére, ${ }^{13}$ também da história da psiquê humana de Sigmund Freud com o Moisés e o Monoteísmo, além da ego-história, trata-se do “[...] retorno do sujeito após um longo eclipse ao peso das estruturas". ${ }^{14}$ Para ele, esse período hermenêutico de fazer historiográfico se caracterizaria pela "[...] variação do enfoque analítico, pela mudança constante da escala, que permitem chegar a significados diferentes com respeito às figuras biografadas" ${ }^{15}$ Esse processo sintetiza-se pela unidade acerca do passado por meio dos olhos das singularidades, os indivíduos não estariam mais sujeitos a organizarem sua escrita biográfica a partir do cronológico e do linear, mas reconheceriam que suas próprias matrizes interpretativas se conectam à pluralidade dos processos históricos, podendo expressar tanto singularidades humanas quanto processos sociais bem delimitados temporalmente.

Atualmente, o historiador “[...] sabe que o enigma biográfico sobrevive à escrita biográfica. A porta permanece escancarada para sempre, oferecida a todos em revisitações sempre possíveis das efrações individuais e de seus traços no tempo". ${ }^{16} \mathrm{O}$ grande desafio biográfico que muitos historiadores tiveram e ainda têm à sua frente, constitui-se na tentativa de responder à realidade social a partir dos elementos que compõem o indivíduo, compreendendo o estudo biográfico como um tipo de abordagem híbrida, um misto de ficção e de realidade.

Dosse é o autor que mais se destaca na forma pela qual aceita o desafio de olhar para relatos de vidas como um verdadeiro "Desafio Biográfico", tentando compor um quadro geral a respeito da escrita biográfica que permita aos seus leitores terem uma perspectiva mais ampliada acerca dessa abordagem de escrita de história, sem, no entanto, enveredar na superficialidade. Em sua abordagem, Dosse descreve-nos o grande percurso pelo qual esse gênero passou até sua renovação recente, e que permitiu aos relatos biográficos acompanhar múltiplas e intensas formas de diálogo com aspectos que vão desde as estruturas sociais e as mentalidades até às formas psicológicas da vida profunda.

\footnotetext{
DOSSE, 2009, p. 231.

GINZBURG, Carlo. O queijo e os vermes. São Paulo: Cia. das Letras, 1987.

2 LE GOFF, Jacques. São Luís. 3. ed. Rio de Janeiro: Record, 2002 [1996].

13 FOUCAULT, Michel. Eu, Pierre Riviere, que degolei minha mãe, minha irmã e meu irmão... um caso de parricídio do século XIX. Rio de Janeiro: Graal, 1977.

14 DOSSE, 2009, p. 252.

15 DOSSE, 2009, p. 359.

16 DOSSE, 2009, p. 410.
} 
"O fato de se considerar o homem como fundamentalmente plural, mantenedor de vínculos diversos, modifica a abordagem do gênero biográfico". ${ }^{17}$

Essa renovação no modo de fazer estudos biográficos permite que, diante de variedades e formas sociais e culturais matizadas no decorrer dos últimos séculos da modernidade, na composição de uma biografia o pesquisador ou escritor invente e crie seu próprio jeito de dizer algo a respeito do outro. Sem deixar de compreender que, ao dissertar sobre um outro ser humano, estará falando de si mesmo, estará a especular de um indivíduo tomado como um sujeito esmiuçado em cacos compondo mosaico, e que ao dar vida a determinados aspectos de seu biografado concederá distintas passagens matizadas aos observadores, colocará à disposição inúmeras cores, tintas, imagens e interpretações que saem do filtro interpretativo e compreensivo de um indivíduo repleto de vinculações vitais a um determinado tempo e lugar, isto é, o biógrafo. Trata-se de uma valorização do indivíduo em sua multiplicidade e pluralidade, e que traz novas problematizações que indicam uma inquietação convidativa, a saber, ao se esquivar ao unitário, do sujeito histórico em seu aspecto singular, não acabaria o biógrafo permitindo uma ruptura e fragmentação alijada de significados? Com respeito a essa aparente aporia entre o indivíduo tomado em sua singularidade e, ao mesmo tempo, em sua pluralidade, Paul Ricouer constrói narrativas biográficas por meio de dois conceitos fundamentais, quais sejam, a ipseidade, que "por sua vez, é a manutenção de si pela recusa da mudança nos compromissos de longa duração", 18 e a mesmidade, que se caracteriza como um conceito de relação entre diferenciados critérios de permanência, quais sejam, identidade numérica, identidade qualitativa, continuidade e, principalmente, princípio de permanência temporal. Sobre estes dois conceitos é que Ricouer constrói a narrativa a respeito da identidade pessoal. Segundo ele, tais princípios se constituem numa forma de permanência no tempo que permite responder à pergunta: "quem sou eu?" A mesmidade encerraria as características próprias a um sujeito, dentro de um lugar e de uma época, que, com o decorrer do processo histórico, altera-se, transforma-se, dinamiza-se. No processo narrativo biográfico nos deparamos com um dilema que poderia ser solucionado, ou encarado com mais razoabilidade, desde a compreensão da identidade pessoal como si mesma, isto é, no sentido do mesmo (idem) possuidor de um núcleo idêntico, estabelecido fixamente, não cambiável, porém, lastreada por uma compreensão da identidade como um si-mesmo (ipse) que indicaria uma dimensão temporal tanto do sujeito quanto de sua ação. Essa noção de ipseidade, colocada por Ricoeur, evidencia, assim, a possibilidade de uma identidade narrativa ipseitiva que inclui mudanças operadas na dinâmica de uma vida. Nesse sentido, tanto a ideia de sujeito (idem) quanto a ideia de sua ação (ipso) estariam vinculadas por uma permanência suscetível, pelo aspecto narrativo, de mediação das

17 DOSSE, 2009, p. 297.

18 BOTTON, João B. Mesmidade, ipseidade e vontade: as aporias da noção ricoeuriana de subjetividade. Impulso, Piracicaba, v. 24, n. 59, 25-34, jan./abr. 2014. Disponível em: <http://dx.doi.org/10.15600/22369767/impulso.v24n59p25-34>. Acesso em: 19 fev. 2018. 
possibilidades de reconstrução de sentidos que abarcam uma vida. A ipseidade e a mesmidade reconstroem assim certa coesão que se centra no fazer e no desfazer de uma vida. Estudar o ser humano em seu habitat é considerar suas imagens plurais formadas sobre ele no decorrer do tempo sob os constantes jeitos de olhar e reolhar da história.

Enfim, notamos que a biografia se "antropomorfiza" sob distintas maneiras e, ao tomar tais contornos, se vê encerrada numa indefinição que é própria da espécie humana. Como personagem, a biografia em si refuta nossos esquecimentos e brinca com nossa memória arteira, como instrumento é alvo de muitas dúvidas e aporias. Assim como Hamlet, ao se questionar sobre a nossa existência ou não, "ser ou não ser", a biografia por ora ganha vida sob o olhar atento de um biógrafo que lhe dá um "efeito de vivido", já em outros momentos se perde perante as incoerências do homem. ${ }^{19}$

Evidentemente que o estudo biográfico traz em si aspectos ficcionais pela necessidade mesma de se imaginar possibilidades que estão fora do alcance do simples historiador. Mas o que dizer das pulsões oníricas que convergem à vigília social dos seres humanos moldadas por meio do mundo da vida? Como, segundo Walter Benjamin (1986), organizar os quadros da psicologia profunda que se expressam pela sobrevivência de aspectos da vida onírica, dos sonhos que mantêm parte significativa dos desejos dos homens e mulheres, e que permitem à vida psíquica a saúde necessária para elaborar as frustrações que as barreiras do superego impõem aos indivíduos? ${ }^{20}$ Como biografar os indivíduos em relações negativas com suas estruturas profundas? Ao biógrafo cumpre preencher as lacunas do relato biográfico por meio das ficções verossímeis e parciais que sejam razoáveis, não necessariamente inventivas de todo, pois calcadas na própria experiência temporal humana algo que universal e local.

\section{Possibilidades e limites: hagiografia, trajetórias e prosopografia}

Nas últimas décadas os historiadores voltaram a se debruçar sobre as biografias como uma possibilidade de fazer história para além da mera forma literária ou do tipo de estudo simplesmente laudatório. Passou-se de uma forma de fazer história historicizante fundamentada em dados e fontes supostamente mais confiáveis, os estudos biográficos deixaram o cenário de segundo plano, uma vez que no fazer tradicional da pesquisa histórica prevalecia a "história das estruturas que passavam a explicar as ações humanas segundo determinações que escapavam a esses homens no mundo". ${ }^{21}$ Neste modelo de

19 SOLANO, Alexandre Francisco. A Biografia Desafiada: os contornos de uma vida por François Dosse. Fênix, Revista de História e Estudos Culturais, v. 7, ano VII, n. 2, maio/ago. 2010. Disponível em: <www.revistafenix.pro.br>. Acesso em: 18 mar. 2018.

20 BENJAMIN, Walter. Magia e técnica, arte e política: ensaios sobre literatura e história da cultura. 2. ed. São Paulo: Brasiliense, 1986.

21 GUIMARÃES, Manoel Luiz Salgado. Prefácio: a biografia como escrita da História. In: SOUZA, Adriana Barreto de. Duque de Caxias: o homem por trás do monumento. Rio de Janeiro: Civilização Brasileira, 2008. p. 21. 
história-problema, de história-questão, a pergunta continua sendo sempre a respeito das estruturas. Pergunta-se pelo que seja a sociedade feudal, a modernidade, a nação, a revolução, as mentalidades ou as formas de subjetivação, enquanto o particular ficará restrito ao aspecto de dado acerca do coletivo, quanto ao particular somente haverá interesse quando ele informar a respeito das questões coletivas. Assim, o verdadeiro tema de um livro a respeito de Dom Pedro II não será sua individualidade, mas a conjuntura da política nacional do segundo império, seu ideal, seus valores e seus paradoxos dos quais ele próprio é um determinado epifenômeno. E, também, um sistema econômico, o "capitalismo", será investigado por meio do estudo biográfico específico no sentido de perceber através desse caso concreto o funcionamento de suas engrenagens e de sua lógica concretizada no dia a dia, e que poderá ser compreendido com mais clareza do que nos tratados ou nas cartas. Neste viés de fazer histórico, “o indivíduo apenas ilustra/reflete uma construção estrutural que lhe ultrapassa. Ele é exemplo, não problema" ${ }^{22}$

O estudo biográfico é uma forma de pesquisa muito desafiadora. Ele tem como desafio ultrapassar o restrito âmbito da trajetória individual, transversalizar aspectos macroestruturais da sociedade e vincular quadros explicativos subjacentes de análise, e organizar o detalhamento biográfico teoricamente alinhado aos fins de ilustração de uma determinada realidade mais ampla ou mesmo indicar ontologias possíveis do tipo que abarcam o indivíduo humano em sua temporalidade e finitude, sem com isso deixar de tomar o indivíduo como problema. A historiografia está fundada continuamente na rejeição do acontecimento único, do acidental, do específico e casual, aprecia-se aquilo que é possível de se tornar objeto de pesquisa científica, isto é, toma-se por científico aquilo que se repete em "inevitáveis variações", aquilo que é regular e possível de ser observado ou refletido a partir do que se deduziriam "leis de caráter mais geral". As problemáticas que levantam a necessidade do uso do estudo biográfico como representativo não seguem as especificidades vinculadas à problemática do fazer da História. A narrativa historiográfica segue os critérios de constância e de continuidade estabelecidos a partir do mundo social, a partir dos eventos já pesquisados e das próprias formas de continuidade e descontinuidade levantadas ao longo do século XX. Por isso, ao refletirmos sobre o lugar do estudo biográfico como uma possibilidade de fazer História, precisamos colocar em questão a possibilidade de outras problemáticas e de outros termos ao debate. A busca pela construção de uma narrativa que traga no cenário elaborado a verdade histórica é um tema posto do qual o estudioso não poderá fugir. No entanto, a falta de documentação, de registros cabíveis e razoáveis conduzirá o estudioso necessariamente à percepção de que sua escrita flerta literariamente com a ficção. Essa tensão dinâmica revelará ao estudioso o caráter híbrido do estudo biográfico. Isso quer dizer que o estudo biográfico se pauta por uma sequencia de interpretações ao longo do tempo imbricadas em fatos e em percepções de valores que organizam os quadros interpretativos que podem estar presentes mesmo

22 AVELAR, 2010, p. 3. 
até em testemunhas oculares dos eventos narrados, não simplesmente a decorrência de uma cadeia longitudinal de compreensões fulcradas por possibilidades e limites exegéticos.

[...] a biografia constitui na verdade o canal privilegiado através do qual os questionamentos e as técnicas peculiares da literatura se transmitem à historiografia. Muito já se debateu esse tema, que concerne sobretudo às técnicas argumentativas utilizadas pelos historiadores. Livre dos entraves documentais, a literatura comporta uma infinidade de modelos e esquemas biográficos que influenciariam amplamente os historiadores. ${ }^{23}$

As variadas formas de escrita permitem novos vieses ao fazer historiográfico. Neste diapasão, a elaboração transversalizada entre hagiografia, trajetórias e prosopografia deram ao estudo biográfico aspectos interessantes. A biografia, numa determinada situação, pode muito bem não ter um valor historiográfico, no entanto, a narrativa como forma de perscrutar situações e descontinuidades temporais permite sondar a própria maneira de o ser humano vivenciar suas potencialidades. Um estudo biográfico pode ter um valor existencial que dialogue, por exemplo, com a capacidade de resiliência do humano ou com a capacidade de resistir à opressão, à violência, à fome, mesmo à morte, mediada essa resistência por todo um mundo simbólico e material comum a todos. Sendo assim, a escrita hagiográfica, a escrita sobre trajetórias e a prosopografia permitem que o estudioso elabore sua narrativa não apenas sobre o que a fonte documental estabelece, mas cria possibilidades interpretativas e hermenêuticas a respeito de determinados eventos.

A hagiografia, tão comemorada nos séculos XII e XIII, deu aos santos uma emolduração mais correlata aos problemas cotidianos. Essa forma de narrativa colocava as figuras beatificadas em situações que se apresentavam a todo e qualquer ser humano do medievo. Há um debate entre a virtude e a práxis. A pessoa virtuosa seria aquela que conseguisse superar suas limitações tanto culturais quanto existenciais. O nobre medieval diante da situação de desafio existencial encontra um ambiente diferente daquele de seu berço, ele agora precisa passar pela prova e ser merecedor. Diz Dosse que:

Ao contrário, a santidade se adquire pela superação da prova, do trágico, e ao preço de uma conversão que decerto se efetua por ingerência divina, mas deve-se também à iniciativa do indivíduo eleito, cuja coragem é um sinal tangível de sua beatitude. ${ }^{24}$

Dosse afirma que a narrativa medieval não fica superada simplesmente, ela passa por mutações e ganha outras tintas na modernidade. O herói medieval dá espaço agora à

23 LEVI, Giovanni. Os usos da biografia. In: AMADO, Janaína; FERREIRA, Marieta de Moraes (Orgs.). Usos e abusos da história oral. Rio de Janeiro: Fundação Getúlio Vargas, 1996. p. 168.

24 DOSSE, 2009, p. 144. 
grande figura, ao filósofo, ao artista, ao poeta, ao literato, até mesmo ao cientista. "Figuras como Dante, Shakespeare, Camões, Rousseau, dentre outros, ganham espaço no gênero biográfico, afirmando aspectos humanitários, que se tornaram latentes naquela época" ${ }^{25}$

A trajetória de vida como construção social e de sentido tanto anterior aos eventos vivenciados quanto posterior aos acontecimentos, é muito discutida como valor historiográfico. Pierre Bourdieu (1996) diz que a trajetória de vida não teria valor teleológico. ${ }^{26}$ A problemática colocada pelo sociólogo francês é a respeito da existência de uma unicidade do ser que seja constante no tempo e no espaço, sendo capaz de ordenar os acontecimentos a favor de um sentido único à vida humana, à vida do indivíduo, em específico. Bourdieu chama a tentativa de se construir uma narrativa acerca da trajetória de uma vida de ilusão biográfica. Segundo o autor, a trajetória de vida teria mais sentido para os outros do que para a pessoa mesma biografada. ${ }^{27}$ Trata-se de uma questão epistemológica, pois são fatos e existências que precisam ser compreendidos, e para tanto é necessário um aporte teórico filosófico.

Por fim, a prosopografia como aspecto fundante da percepção dos acontecimentos coletivos se constitui numa tarefa importante para o estudo biográfico uma vez que configura o meio ambiente dos indivíduos sua coletividade na qual eles vivenciam suas individualidades. Conforme Lawrence Stone:

A prosopografia é a investigação das características comuns do passado de um grupo de atores na história através do estudo coletivo de suas vidas. O método empregado é o de estabelecer o universo a ser estudado e formular um conjunto uniforme de questões - sobre nascimento e morte, casamento e família, origens sociais e posições econômicas herdadas, lugar de residência, educação, tamanho e origens das fortunas pessoais, ocupação, religião, experiência profissional etc. Os vários tipos de informação sobre indivíduos de um dado universo são então justapostos e combinados e, em seguida, examinadas por meio de variáveis significativas. Essas são testadas a partir de suas correlações internas e correlacionadas com outras formas de comportamento e ação. ${ }^{28}$

Não há uma única definição do conceito de prosopografia, há uma multiplicidade de compreensões, porém existe algo que é comum em quase todas as definições, a saber, o estudo do indivíduo a partir da sua totalidade em que está imerso. É nesse sentido que a definição de Stone compreende a relação do indivíduo com a sua totalidade sociológica.

5 SOLANO, 2018, p. 5.

26 BOURDIEU, Pierre. A ilusão biográfica. In: FERREIRA, Marieta de Moraes; AMADO, Janaína (Orgs.). Usos e abusos da história oral. Rio de Janeiro: Fundação Getúlio Vargas, 1996.

27 MONTAGNER, Miguel Ângelo. Trajetórias e biografias: notas para uma análise bourdieusiana. Sociologias, Porto Alegre, ano 9, n. 17, p. 240-264, jan./jun. 2007.

28 STONE, Laurence. Prosopography. Rev. Sociol. Polit, Curitiba, v. 19, n. 39, jun. 2011. Disponível em: <http://www.scielo.br/pdf/rsocp/v19n39/a09v19n39.pdf>. Acesso em: 2 abr. 2018. 
Por isso, a narrativa acerca de um indivíduo precisa levar em conta sua coletividade, uma vez que é ela que moldará sua individualidade.

\section{Conclusão}

A narrativa a respeito de uma vida está implicada em muitos desafios. O uso do estudo biográfico na pesquisa histórica traz consigo os riscos, a críticas e as possibilidades de verificar a relação entre narrador e narrado desde uma perspectiva que consiga avaliar a própria forma dos indivíduos em estabelecerem fatos acerca de si mesmos como um projeto de existência.

Nesse sentido, percebemos como o estudo biográfico ao fazer uso da prosopografia, dos relatos de trajetória e da própria hagiografia - grandes personagens da história - se constitui num recurso interessante para a apreensão do papel histórico desempenhado por determinados indivíduos e permite revelar a aporia presente neste tipo de pesquisa, a saber, a concepção do indivíduo como problema para além das estruturas biológicas e sociais.

\section{Referências}

AVELAR, Alexandre de Sá. Escrita biográfica e escrita da história no pensamento de Wilhelm Dilthey. Dimensões, v. 38, p. 120-142, jan./jun. 2017. Disponível em: <www.periodicos.ufes.br/dimensoes/article/viewFile/16809/11599>. Acesso em: 05 abr. 2018.

. Escrita da História, Escrita Biográfica: limites, tensões e possibilidades. ANAIS DO XX ENCONTRO REGIONAL DE HISTÓRIA: História e Liberdade. ANPUH/SP - UNESP - 06 a 10 de setembro de 2010, Franca. CD-ROM.

BENJAMIN, Walter. Magia e técnica, arte e política: ensaios sobre literatura e história da cultura. 2. ed. São Paulo: Brasiliense, 1986.

BORGES, Raquel Czarneski. A Escrita Biográfica: reflexões acerca das possibilidades narrativas. XII ENCONTRO ESTADUAL DE HISTÓRIA ANPUH/RS, de 11 a 14/08/2014, Universidade do Vale do Rio dos Sinos - UNISINOS - São Leopoldo, RS - Brasil.

Disponível em: <http:/ / www.eeh2014.anpuhrs.org.br/resources/anais/30/1405476586_ARQUIVO_aescritabiograficatexto.pdf>. Acesso em: 08 mar. 2018.

BOTTON, João B. Mesmidade, ipseidade e vontade: as aporias da noção ricoeuriana de subjetividade. Impulso, Piracicaba, v. 24, n. 59, 25-34, jan./abr. 2014. Disponível em: <http:/ /dx.doi.org/10.15600/2236-9767/impulso.v24n59p25-34>. Acesso em: 19 fev. 2018.

BOURDIEU, Pierre. A ilusão biográfica. In: FERREIRA, Marieta de Moraes; AMADO, Janaína (Orgs.). Usos e abusos da história oral. Rio de Janeiro: Fundação Getúlio Vargas, 1996. 
DILTHEY, Wilhelm. A construção do mundo histórico nas ciências humanas. São Paulo: EDUNESP, 2010.

DOSSE, François. O Desafio Biográfico: escrever uma vida. São Paulo: EDUSP, 2009.

FOUCAULT, Michel. Eu, Pierre Riviere, que degolei minha mãe, minha irmã e meu irmão... um caso de parricídio do século XIX. Rio de Janeiro: Graal, 1977.

GINZBURG, Carlo. O queijo e os vermes. São Paulo: Cia. das Letras, 1987.

GUIMARÃES, Manoel Luiz Salgado. Prefácio: a biografia como escrita da História. In: SOUZA, Adriana Barreto de. Duque de Caxias: o homem por trás do monumento. Rio de Janeiro: Civilização Brasileira, 2008.

LE GOFF, Jacques. A história nova. São Paulo: Martins Fontes, 1990.

. São Luís. 3. ed. Rio de Janeiro: Record, 2002 [1996].

LEVI, Giovanni. Os usos da biografia. In: AMADO, Janaína; FERREIRA, Marieta de Moraes (Orgs.). Usos e abusos da história oral. Rio de Janeiro: Fundação Getúlio Vargas, 1996.

MONTAGNER, Miguel Ângelo. Trajetórias e biografias: notas para uma análise bourdieusiana. Sociologias, Porto Alegre, ano 9, n. 17, p. 240-264, jan./jun. 2007.

SOLANO, Alexandre Francisco. A Biografia Desafiada: os contornos de uma vida por François Dosse. Fênix, Revista de História e Estudos Culturais, v. 7, ano VII, n. 2, maio/ago. 2010. Disponível em: <www.revistafenix.pro.br>. Acesso em: 18 mar. 2018.

STONE, Laurence. Prosopography. Rev. Sociol. Polit, Curitiba, v. 19, n. 39, jun. 2011. Disponível em: <http://www.scielo.br/pdf/rsocp/v19n39/a09v19n39.pdf>. Acesso em: 2 abr. 2018. 